\title{
STRUCTURE OF A FLAX THRESHING MASS DEVICE
}

\author{
Edmund Kamiński ${ }^{\mathrm{a}}$, Victor Iofimovich Kocuba ${ }^{\mathrm{b}}$, Maciej Kubon' ${ }^{\mathrm{c}}$, Vjacheslav Sharshunov ${ }^{\mathrm{d}}$ \\ ${ }^{\text {a }}$ Institute of Technology and Life Sciences, Masovian Research Centre in Kludzienko \\ ${ }^{\mathrm{b}}$ Belarusian State Agricultural Academy, Gorki, Belarus \\ ${ }^{\mathrm{c}}$ Institute of Agricultural Engineering and Informatics, University of Agriculture in Krakow \\ ${ }^{\mathrm{d}}$ Belarusian State Agricultural Academy, Gorki, Belarus \\ Corresponding author: e-mail: e.kaminski@itep.edu.pl
}

\begin{tabular}{|c|c|}
\hline ARTICLE INFO & ABSTRACT \\
\hline $\begin{array}{l}\text { Article history: } \\
\text { Received: June } 2016 \\
\text { Received in the revised form: } \\
\text { August } 2016 \\
\text { Accepted: September } 2016 \\
\end{array}$ & \multirow{2}{*}{$\begin{array}{l}\text { The object of the research consisted of a roller threshing unit with } \\
\text { a profile elastic working surface of a parabolic type and a triangle one } \\
\text { with rollers which turn concurrently with various angular speeds. Two } \\
\text { rollers with } 150 \text { and } 300 \mathrm{~mm} \text { were investigated. The process of seeds } \\
\text { separation from the threshing mass took place at its moisture of } 10 \text { to } \\
35 \% \text {. The relation of mixtures in the straw mass in a mass relation was } \\
\text { changing within } 10 \text { to } 35 \% \text { with the length of stalks from } 20 \text { to } 400 \\
\mathrm{~mm} \text {. The amount of the material provided for threshing was varied } \\
\text { from } 0.27 \text { to } 0.52 \mathrm{~kg} \cdot \mathrm{s}^{-1} \cdot \mathrm{m}^{-1} \text { and the slot between the rollers from } \\
1.0 \text { to } 6.0 \mathrm{~mm} \text {. The width of the base of notches located on the work- } \\
\text { ing surface of drums was within } 25 \text { to } 150 \text { mm, the height of notches } \\
\text { on rollers was within } 10 \text { to } 60 \text { mm. Kinematic conditions of rollers } \\
\text { operation were within } 1.0 \text { to } 1.5 \text {. As a result of the research it was } \\
\text { determined that a parabola is the optimal form of the profiled surface } \\
\text { of rollers in a cross section. It ensures more effective seeds separation } \\
\text { than a triangle configuration of drums. This conclusion is also con- } \\
\text { firmed by a theoretical discussion and is explained with the fact that } \\
\text { the parabolic form of notches has a bigger surface than the triangle } \\
\text { one and that they affect more seed-bags which leads to the increase of } \\
\text { the seeds separation degree. The laboratory research allowed determi- } \\
\text { nation of rational ranges of parameters changes during flax mass } \\
\text { threshing. }\end{array}$} \\
\hline $\begin{array}{l}\text { Key words: } \\
\text { flax harvesting, } \\
\text { flax threshing machine, } \\
\text { separator, } \\
\text { flax seeds }\end{array}$ & \\
\hline
\end{tabular}

\section{Введение}

Применяемые в настоящее время технологии уборки сноповым, комбайновым или раздельным способами приводят к недомолоту и безвозвратной потере до 30\% семян льна (Вадим, 2014; Диренко и др., 2003; Котченков и др., 2006). Поэтому в настоящее время применяется технология уборки семян льна с обработкой вороха на стационаре. Такая технология позволяет свести к минимуму этот недостаток, а также дает значительное преимущество, однако реализация возможна при разработке новых и усовершенствованных уже известных конструкций машин и оборудования. (Каминьски и др. 2014а; 2014в). 
Применяемые в настоящее время машины для обмолота семенного льновороха имеют высокую степень травмирования семян - до 30\%. Поэтому является актуальной разработка и исследование новых молотильных устройств, которые отвечают современным технологическим требованиям получения семян. (Шаршунов и др. 1998; 2000; 2001).

Анализ существующих молотильных устройств позволяет сделать вывод, что наиболее рациональным вариантом является, обмолот льновороха молотильным аппаратом вальцового типа с эластичной рабочей поверхностью (Ковалев, 2006; Маркс, 2012; Сотченков, 2007).

\section{Цель исследований}

Целью исследований является увеличение полноты выделения семян из семенных коробочек, содержащихся в льноворохе, путем выбора конструктивных параметров молотильного устройства и оптимизации режима его работы.

\section{Предмет и методика исследований}

В предлагаемом молотильном устройстве для обмолота семенного вороха льна, вальцы выполнены в виде цилиндров с эластичной рифленой рабочей поверхностью, выступы которой плавно переходят во впадины по линии их соединения, причем риф одного вальца входит во впадину другого таким образом, что между их поверхностями образуется криволинейный молотильный зазор (Рис. 1).

Вальцы вращаются на встречу друг другу с разными угловыми скоростями. Расстояние между осями вальцов регулируется в необходимых пределах. При вращении вальца 1 навстречу вальцу 2 с различными угловыми скоростями, поступает материал в молотильный зазор 3. Образованная рифленая поверхность вальцов 1 и 2, оказывается изгибающее в поперечном и продольном сечение, вытирающее в продольном направлении воздействие, приводящее к выделению семян. Рифленая поверхность вальцов позволяет увеличить площадь контакта в $\pi / 2$ раз, что увеличивает производительность молотильного устройства. 
Structure of a flax...

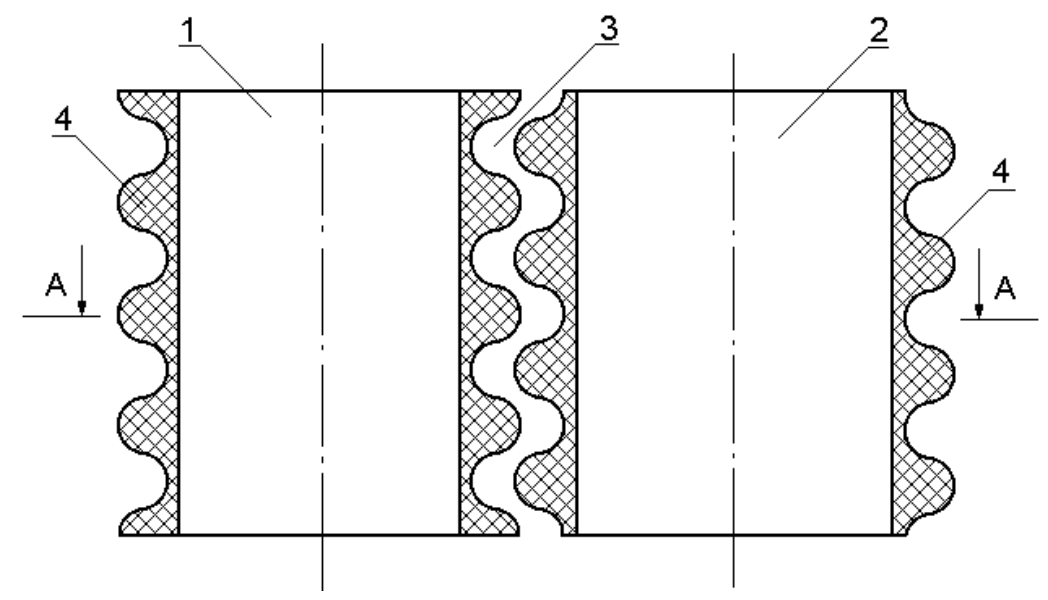

a

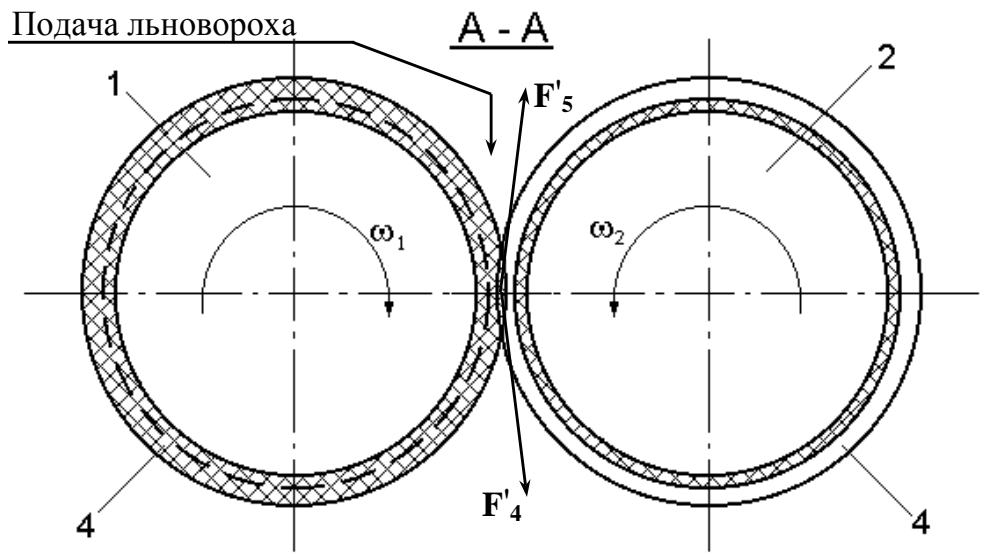

б

1 и 2 - вальцы; 3 - молотильный зазор; 4 - эластичная рифленая поверхность; $F_{4}^{\prime}, F_{5}^{\prime}$ - силы растирания

Рисунок 1. Схема молотильного устройства с эластичной рифленой рабочей поверхностью

Полученные зависимости определяют координат точек касания коробочек льна с рабочей поверхностью вальцов. Углы захвата молотильным устройством коробочки льна (Рис. 2) зависят от радиусов вальцов, размеров коробочки льна, а также угла трения коробочки льна о рабочую поверхность вальцов (Шаршунов и др., 2001). 


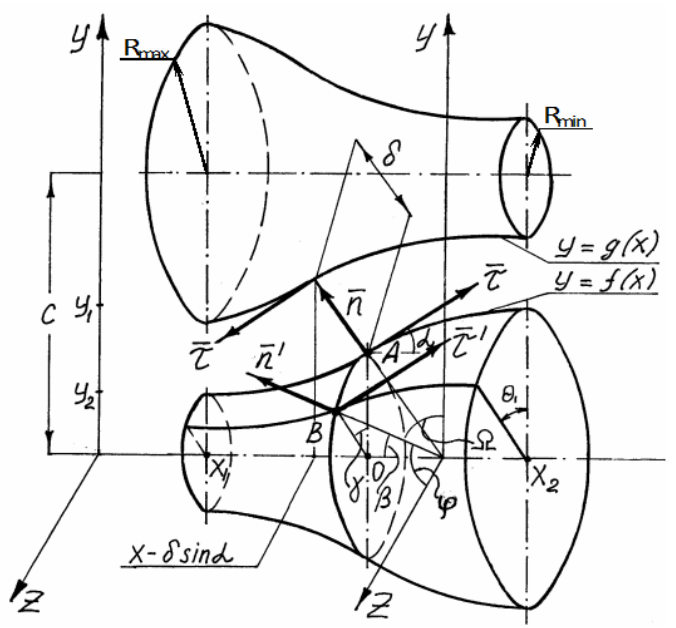

Рисунок 2. Схема к определению углов захвата коробочки льна молотильньм устройством

$$
\begin{gathered}
\cos \theta_{1}=\frac{\left[c-R_{2} \cdot \cos \theta_{2} \cdot\left(1+\frac{r_{K}}{R_{2}} \cdot \cos \alpha\right)\right]}{\left(R_{1}+r_{K} \cdot \cos \alpha\right)}, \\
\sin \theta_{2}=\frac{R_{1} \cdot \sin \theta_{1} \cdot\left(1+\frac{r_{K}}{R_{1}} \cdot \cos \alpha\right)}{\left(R_{2}+r_{K} \cdot \cos \alpha\right)} .
\end{gathered}
$$

Со стороны молотильных вальцов на коробочку льна действуют силы, возникающие за счет трения вальцов о поверхность коробочки. Путь, проходимый коробочкой льна в молотильном зазоре, определяется по зависимости:

$$
\begin{gathered}
S_{1}=2 \cdot R_{1} \cdot \sin \theta_{1}=2 \cdot R_{1} \cdot \sqrt{1-\frac{c^{2}-\left(R_{1}+r \cdot \cos \alpha\right)^{2}+\left(R_{2}+r \cdot \cos \alpha\right)^{2}}{2 \cdot c \cdot\left(R_{2}+r \cdot \cos \alpha\right)}}, \\
S_{2}=2 \cdot R_{2} \cdot \sin \theta_{2}=2 \cdot R_{2} \cdot \sqrt{1-\frac{c^{2}-\left(R_{2}+r \cdot \cos \alpha\right)^{2}+\left(R_{1}+r \cdot \cos \alpha\right)^{2}}{2 \cdot c \cdot\left(R_{1}+r \cdot \cos \alpha\right)}},
\end{gathered}
$$

где: $S_{1}$ и $S_{2}$ - длина пути, проходимого коробочкой льна в молотильном зазоре, на протяжении которого на нее оказывается разрушающее воздействие со стороны молотильных вальцов 1 и 2 (Рис. 3). 
Structure of a flax...

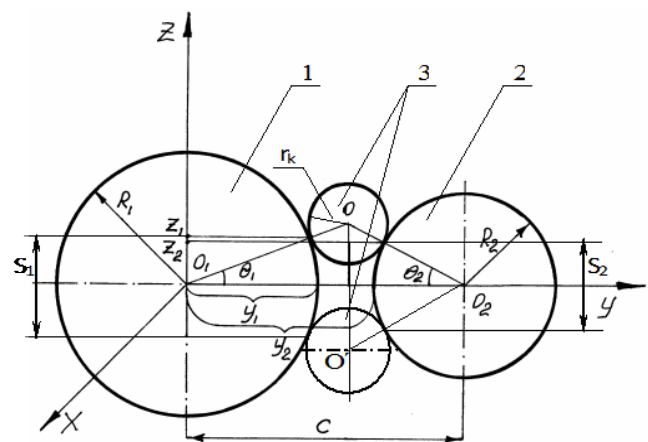

1 и 2 - вальцы; 3 - коробочка льна

Рисунок 3. Схема к определению пути, проходимого коробочкой в молотильном зазоре

Обоснованы радиусы кривизны вальцов исходя из условия захвата коробочки льна рабочими поверхностями молотильных вальцов. Затягивание коробочки льна вальцами будет происходить в случае когда (Рис. 4)

$$
\theta_{1}+\theta_{2} \leq 2 \cdot \varphi
$$

где:

$\theta_{1} \quad$ - угол захвата частицы вальцом меньшего диаметра;

$\theta_{2} \quad$ - угол захвата частицы вальцом большего диаметра;

$\varphi$ - угол трения коробочки о поверхность вальцов, определяемый коэффициентом трения и весом головки льна.

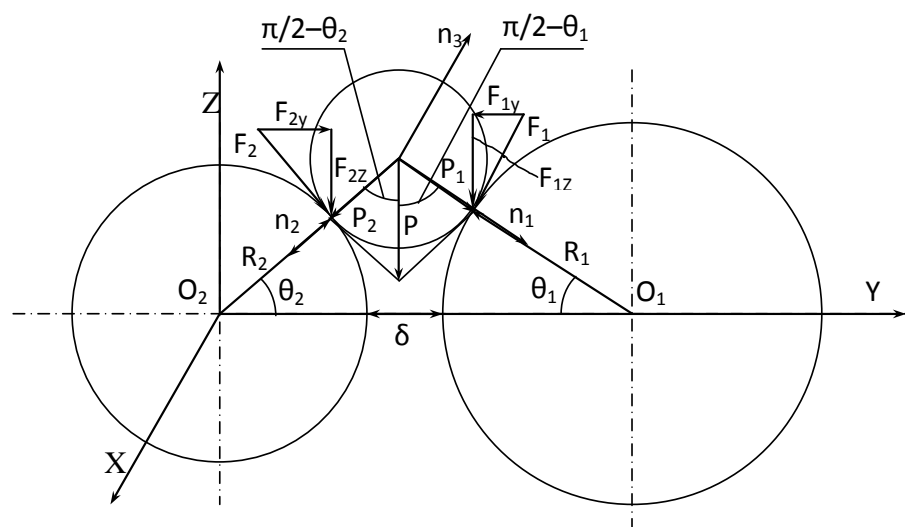

Рисунок 4. Схема для определения зазора между вальцами и радиусов вальцов

Исходя из условия захвата частицы (5) радиусы вальцов определяются по зависимостям. 


$$
\begin{gathered}
R_{1}=\frac{2 \cdot r_{K} \cdot \cos \left(2 \varphi-\theta_{2}\right)-\delta}{2 \cdot\left(1-\cos \left(2 \varphi-\theta_{2}\right)\right)}, \\
R_{2}=\frac{2 \cdot r_{K} \cdot \cos \theta_{2}-\delta}{2 \cdot\left(1-\cos \theta_{2}\right)} .
\end{gathered}
$$

где:

$r_{K} \quad$ - радиус коробочки льна, (м)

$\delta \quad$ - величина зазора между вальцами, (м)

Из полученных формул можно сделать вывод, что радиусы вальцов зависят от гранулометрического состава обмолачиваемого материала, зазора между вальцами и коэффициента трения обрабатываемого материала о рабочую поверхность вальцов.

Пропускная способность вальцового молотильного аппарата с криволинейной рабочей поверхностью (Рис. 5) определится по зависимости:

$$
q_{M}=\frac{\sqrt{16 \cdot h^{2}+\bar{l}^{2}} \delta \cdot \gamma \cdot\left[\omega_{1}^{\prime} \cdot\left(R_{1}+\frac{h}{2}\right)+\omega_{2}^{\prime} \cdot\left(R_{2}+\frac{h}{2}\right)\right]}{4 \cdot \bar{l}} .
$$

где:

$h$ - высота рифов вальцов, (м)

$\bar{l}$ - длина основания рифов вальцов, (м)

$\gamma \quad$ - плотность льновороха, поступающего на обмолот, $\left(\right.$ кг· $\left.\mathrm{M}^{-3}\right)$

$\omega_{1}^{\prime}$ и $\omega_{2}^{\prime}-$ угловая скорость вращения первого и второго вальцов, соответственно, $\left(\mathrm{c}^{-1}\right)$

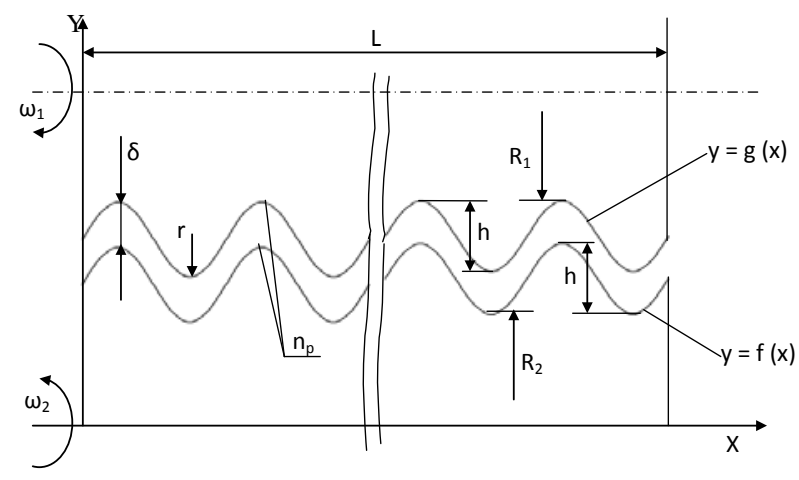

Рисунок 5. Схема к определению пропускной способности вальцов

Из выражения (8) видно, что пропускная способность молотильного аппарата вальцового типа с рифленой рабочей поверхностью зависит от геометрических и кинематических параметров вальцов.

Степень выделения семян, которая устанавливается агротехническими требованиями, определяется по формуле: 
Structure of a flax...

$$
E=1-\left(\frac{\omega_{1}}{\omega_{2}}\right)^{2} \frac{\left[\cos \left(2 \varphi-\theta_{2}\right)-\delta\right]^{2}\left(1-\cos \theta_{2}\right)^{2}}{\left(\cos \theta_{2}-\delta\right)^{2}\left[1-\cos \left(2 \varphi-\theta_{2}\right)\right]^{2}} .
$$

Из зависимости (9) видно, что степень выделения семян зависит от частоты вращения, геометрических параметров вальцов, молотильного зазора между ними и коэффициента трения семенного вороха льна о рабочую поверхность вальцов.

\section{Результаты исследований}

Проведенные теоретические исследования процесса обмолота льновороха вальцовым молотильным аппаратом с рифленой рабочей поверхностью позволяют определить:

- силы, действующие на коробочку льна, находящуюся в молотильном зазоре;

- оптимальную форму рабочей поверхности вальцов;

- оптимальные значения радиусов вальцов и зазора между ними;

- пропускную способность вальцового молотильного устройства;

- частоту вращения вальцов;

- показатель кинематического режима вальцов;

- эффективность процесса обмолота семенного вороха льна.

Для получения математической модели процесса обмолота, и определения его оптимальных параметров были обоснованы основные факторы, оказывающие наиболее существенное влияние на параметры оптимизации процесса обмолота.

Установлены рациональные интервалы варьирования факторов при обмолоте семенного вороха льна. Диаметр вальцов - 190-240 мм; зазор между вальцами 0,002-0,004 м; пропускная способность молотильного аппарата на единицу длины поверхности вальцов - 0,32-0,47 кг $\mathrm{c}^{-1} \cdot \mathrm{M}^{-1}$; влажность льновороха $-15-20 \%$; показатель кинематического режима $\lambda-1,25-1,35$; частота вращения вальцов - 160 220 мин $^{-1}$; содержание путанины в ворохе $-10-25 \%$; ширина основания рифов - 2560 мм; высота рифов - 10-30 мм. За функцию отклика $E$ была принята степень выделения семян, т.е. количество семян, выделенных из льновороха за один проход через молотильный зазор и выраженное в процентах ко всем семенам, находящимся в коробочках в необмолоченном льноворохе.

В результате проведенных исследований получили математическую модель процесса обмолота:

$$
\begin{aligned}
& E=17,21+2313,33 \cdot \delta+0,1 \cdot \omega+115,22 \cdot \lambda+1,75 \cdot \delta \cdot \omega- \\
& -1716,67 \cdot \delta \cdot \lambda-0,0058 \cdot \omega \cdot \lambda-189444,44 \cdot \delta^{2}-0,00023 \cdot \omega^{2}-46,07 \cdot \lambda^{2}
\end{aligned}
$$

По результатам исследований можно сделать вывод, что область оптимума исследуемых факторов находится в следующих пределах: зазор между вальцами 0,0027-0,0032 м; частота вращения вальцов - 205-215 мин ${ }^{-1}$; показатель кинематического режима вальцов - 1,25-1,35.

Экспериментальное молотильное устройство было установлено на модернизированной молотилке МЛВ-2,0М. 
При проведении производственных испытаний проводились исследования зависимости степени выделения семян $E$, (\%); степени травмирования семян $T$, (\%) и энергоемкости процесса обмолота $N_{O Б}$ от частоты вращения вальцов $\omega$, мин ${ }^{-1}$; влажности льновороха, поступающего на обмолот $W$, (\%); величины молотильного зазора $\delta$, мм и пропускной способности молотильного аппарата на единицу длины поверхности вальцов $q_{M}, \kappa^{\circ} \cdot \mathrm{c}^{-1} \cdot \mathrm{M}^{-1}$ (Рис. 6-8).

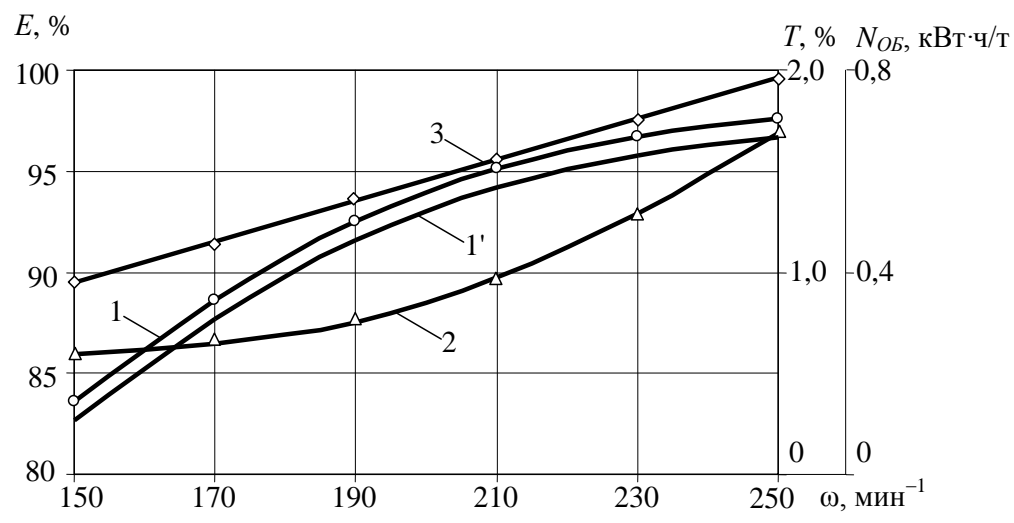

1 - степень выделения семян (экспериментальная кривая); 1' - степень выделения семян (теоретическая кривая); 2 - степень травмирования семян; 3 - энергоемкость процесса обмолота

Рисунок 6. Показатели работы предлагаемого вальцового молотильного устройства в зависимости от частотьы вращеения вальцьов

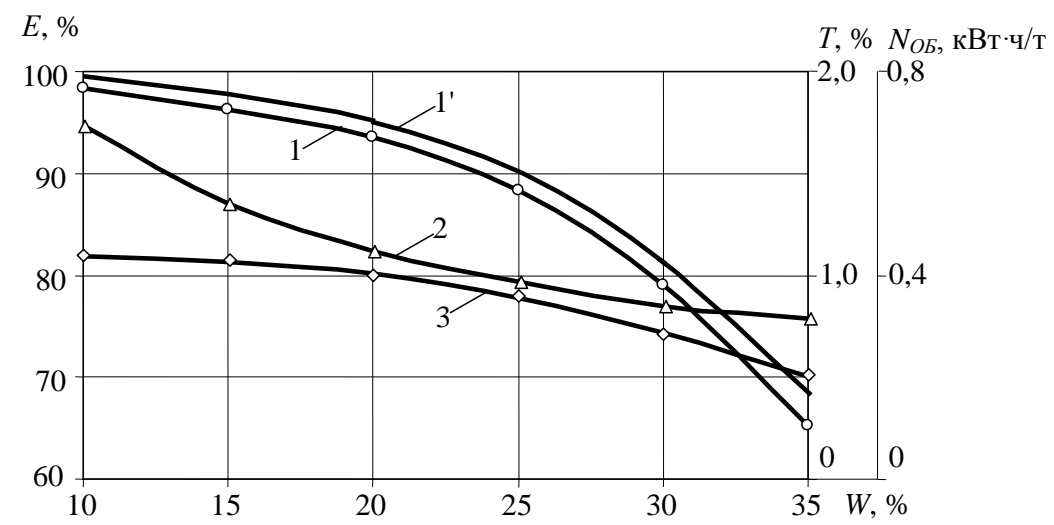

1 - степень выделения семян (экспериментальная кривая); 1' - степень выделения семян (теоретическая кривая); 2 - степень травмирования семян; 3 - энергоемкость процесса обмолота

Рисунок 7. Показатели работь предлагаемого вальцового молотильного устройства в зависимости от влажности льновороха 
Structure of a flax...

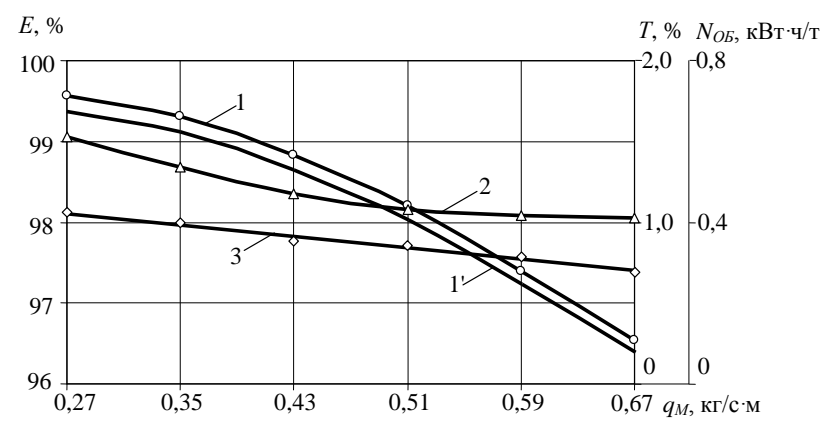

1 - степень выделения семян (экспериментальная кривая); 1' - степень выделения семян (теоретическая кривая); 2 - степень травмирования семян; 3 - энергоемкость процесса обмолота

Рисунок 8. Показатели работьл разработанного вальцового молотильного устройства в зависимости от пропускной способности молотильного аппарата на единицу длины поверхности вальијов

Проведенные производственные испытания подтвердили полученные оптимальные значения кинематических и технологических параметров вальцового молотильного устройства с эластичной рифленой рабочей поверхностью при обмолоте семенного вороха льна.

Для упрощения процедуры расчета значений молотильного зазора $\delta$, пропускной способности молотильного аппарата $q_{M}$, частоты вращения вальцов $\omega$ и показателя кинематического режима $\lambda$ нами предлагается использование номограммы (Рис. 10).
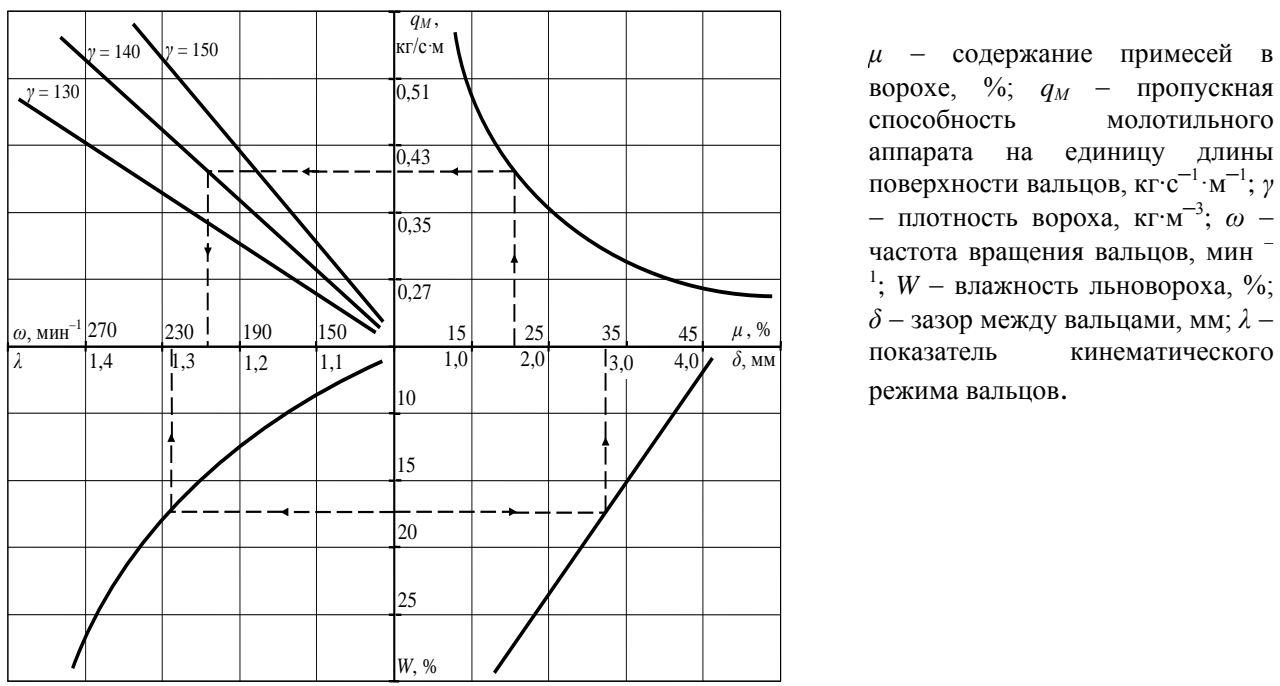

Рисунок 10. Номограмма для выбора технологических параметров молотильного устройства вальцьового типа с эластичной рифленой рабочей поверхностью 


\section{Вывод}

В результате производственных испытаний в льноводческих хозяйствах модернизированной стационарной молотилки МЛВ-2,0М с молотильным аппаратом вальцового типа с эластичной рифленой рабочей поверхностью установлено, что в сравнении с использованием льномолотилок МЛВ-2,0 и МВ-2,5А при обмолоте семенного вороха льна обеспечивается увеличение степени выделения семян соответственно на 6-8\% и 4-5\%, снижение степени повреждения и микроповреждений семян на 2,5-3,5\% и 10-13\%, энергоемкости процесса обмолота на $17-19 \%$ и 52-54\%,. увеличение пропускной способности молотильного аппарата на $10-12 \%$ (в сравнении с МЛВ-2,0). Экономический эффект от внедрения разработанного молотильного устройства по сравнению с молотилкой МЛВ-2,0 составляет 20,8 евро., по сравнению с молотилкой МВ-2,5A - 31,2 евро на одну тонну семян льна.

\section{Литература}

Вадим, М. (2014). Машины для обмолота снопов льна и обработки льняного вороха. Главная страница «Сельское хозяйство» Сайт рефератов.

Диденко, Н. Ф., Черников, В. Г., Ковалев, М. М. (2003). Льноуборочная техника: состояние и направление развития. Тракторы и сельскохозяйственные машины. № 11, 35-38.

Kamiński, E., Śarśunov, V. A., Kruglenja, V. E. (2014a). Fizyczno-mechaniczne i technologiczne właściwości lnianej masy omłotowej i jej części składowych. Problemy Inżynierii Rolniczej, 2(84), 63-75.

Kamiński, E., Śarśunov, V. A., Kruglenja, V. E. (2014b.) Wstępna obróbka masy omłotowej lnu włóknistego w celu pozyskiwania nasion. Problemy Inżynierii Rolniczej, 2(84), 77-86.

Ковалев, М. М. (2006). Прогрессивные технологии и техника для производства льнопродукции. Техника и оборудование для села, 11, 18-20.

Котченков, С. А., Максимов, К. В., Сотченков, А. В. (2006). Анализ обеспеченности хозяйств Псковской области в льноуборочной технике. Сборник научных трудов СПбГАУ Спб. 72 76.

Marks, N. (2012). Maszyny do czyszczenia i sortowania płodów rolnych. Wydawnictwo Uniwersytetu Rolniczego w Krakowie. Skrypt. ss. 63.

Сотченков, А. В. (2007). Повышение эффективности переработки льновороха путем совершенствования рабочих органов устройства разделения насыпи. Великие Луки, 140. Электронная библиотека диссертации.

Шаршунов, В. А., Кругленя, В. Е., Кудрявцев, А. Н, Курзенков, С. В. (1998). Dobór parametrów konstrukcyjnych zespołu młócącego do lnu. Problemy Inżynierii Rolniczej, 4(22), 63-67.

Шаршунов, В. А., Кругленя, В. Е., Кудрявцев, А. Н. (2000). Усовершенствованная молотилка льновороха МЛВ-2,0М. Международный аграрный журнал. № 12, 40-42.

Шаршунов, В. А., Кругленя, В. Е., Кудрявцев, А. Н., Алексеенко, А. С., Масловский, А. В (2001). Методика выбора параметров вальцового молотильного устройства. Агропанорама. № 6, 7-9. 
Structure of a flax...

\section{KONSTRUKCJA URZĄDZENIA DOMLACAJĄCEGO LNIANA MASE OMLOTOWA}

Streszczenie. Obiektem badań był walcowy zespół omłotowy z profilowaną elastyczną powierzchnią roboczą typu parabolicznego i trójkątnego o walcach obracających się współbieżnie z różnymi prędkościami kątowymi. Badano dwa walce o średnicach 150 i $300 \mathrm{~mm}$. Proces wydzielania nasion z masy omłotowej zachodził przy jej wilgotności od 10 do 35\%. Stosunek domieszek w masie słomiastej, w stosunku masowym, zmieniał się w przedziale od 10 do $35 \%$ z długością źdźbeł od 20 do $400 \mathrm{~mm}$. Zmieniano ilość podawanego materiału do omłotu w zakresie od 0,27 do $0,52 \mathrm{~kg} \cdot \mathrm{s}^{-1} \cdot \mathrm{m}^{-1}$ i szczelinę między walcami od 1,0 do $6,0 \mathrm{~mm}$. Szerokość podstawy karbów znajdujących się na po-wierzchni roboczej bębnów zmieniała się w przedziale od 25 do $150 \mathrm{~mm}$, wysokość karbów na walcach zmieniała się w zakresie od 10 do $60 \mathrm{~mm}$. Kinematyczne warunki pracy walców zmieniały się w przedziale od 1,0 do 1,5. W rezultacie przeprowadzonych badań ustalono, że optymalną formą profilowanej powierzchni walców, w przekroju poprzecznym, jest parabola. Zapewnia ona bardziej efektywne wydzielanie nasion w porównaniu z trójkątną konfiguracją bębnów. Wniosek ten potwierdzają też rozważania teoretyczne i objaśniany jest tym, że forma paraboliczna garbów posiada większą powierzchnię niż trójkątna i w większym stopniu oddziaływają na torebki z nasionami, co prowadzi do zwiększenia stopnia wydzielania nasion. Przeprowadzone badania laboratoryjne pozwoliły określić racjonalne przedziały zmian parametrów podczas omłotu masy słomiastej lnu.

Słowa kluczowe: zbiór lnu, młocarnia do lnu, czyszczalnia, nasiona lnu 